This is the peer reviewed version of the following article: Watson, R. (2019), Predatory journals and the pollution of academic publishing. J Nurs Manag. Accepted Author Manuscript., which has been published in final form at https://doi.org/10.1111/ jonm.12739. This article may be used for non-commercial purposes in accordance with Wiley Terms and Conditions for Use of Self-Archived Versions.

\title{
Predatory journals and the pollution of academic publishing
}

\section{Roger Watson}

I am writing this in China and, looking from my hotel room, I can barely see beyond the buildings on the other side of the street. It's pollution; it obscures vision, and exposure has adverse effects on health. I think 'pollution' is an excellent metaphor for what we are currently seeing in academic publishing as a result of the seemingly inexorable increase in the number of predatory publishers and the 'fruits' of their labour, the predatory journals and predatory conferences. It has recently been estimated that there are over 10,000 predatory journals (Watson 2018a) and that the real number may be unknown. Like viruses, which can mutate and adapt to prevent detection and destruction by the immune system, new predatory journals appear using various and sometimes random combinations of subject names in their titles to distinguish them from some previous manifestation. Names are often very general, inclusive and bizarre. For example, the Journal of Nursing and Healthcare and the Nursing and Healthcare Journal both appear under the same link

(http://www.iqscholar.com/nursing.html; accessed 25 November 2018). The email of invitation this journal sends contains the signature and ridiculous 'Greetings' and the link to the Editorial Board contains a list of people, most of whom probably do not know they are listed, represented by the most distorted and low-quality photographs which have clearly been screenshot from university websites and pasted in. Incidentally, other sites such as 'omicsonline' and 'opastonline' list journals with the same titles - all predatory. Be under no illusions, the predatory publishing industry is a hydra-headed monster which is only out to achieve one thing: profit, and at the expense of your reputation.

I am sure that I am preaching to the aware but some nurse managers wishing to publish the results of their work may be less aware of the predatory publishing industry. However, if they are successful in publishing they will soon be inundated and tempted to respond to the flattery. After all, plenty of academics, who should know better, fall for the con. On the other 
hand, very few readers will not suffer the daily onslaught of emails of invitation, inevitably greeting you in superlative terms, to publish in their journal or attend a conference at which your presence is 'expected'. These are the predators and the emails are completely unstoppable. You can delete and spam - they find a way back in - you can click on the 'unsubscribe' link - it is usually inactive - and they will continue their daily drip, filling your email box to capacity and obscuring the view of those emails that matter...pollution! Despite the temptation to reply in the negative with a forceful message to desist, you must never do this. The person - if there is one at the receiving end - or the 'bots' they use, assume you are interested and begin to escalate the situation; more emails. All you can do is delete and carry on with your work until the next wave of pollution arrives.

Beyond not responding and never submitting anything, individual action is virtually useless in stopping the pollution of the academic publishing environment. Just like atmospheric pollution, where individual action has some - but little - effect, only sustained collective action will be effective. Unfortunately, there is little evidence that this is taking place. Moreover, it is not easy to find a definitive list of predatory journals. Since the demise of Beall's list (Watson 2017) - still available in a cached form online but only accurate up to 2017

(http://openscience.ens.fr/ABOUT_OPEN_ACCESS/BLOGS/2017_01_23_Jeffrey_Beall_las t_list_of_predatory_journals.pdf; accessed 25 November 2018) - the alternative is Cabell's List (https://scholarlykitchen.sspnet.org/2017/07/25/cabells-new-predatory-journal-blacklistreview/; accessed 25 November 2018) but this costs several thousand pounds sterling to access and I am unaware of any universities which have subscribed (I welcome information on any which have). In the UK, Research England have not helped by saying that outputs from predatory journals will be treated equally to other outputs in the forthcoming 2020 Research Excellence Framework (Watson 2018a). Admittedly, it would not be easy for 
Research England to identify all the predatory journals that may be returned; nevertheless, the members of the sub-panels who assess the research should be aware and, if in doubt about the provenance of a journal, could ask for it to be checked.

That the predatory publishers exist and persist is proof that they are making a profit. Their investment in the processes they oversee is minimal: they have dreadful websites, no evidence of editorial management systems and do little to produce articles in the usual format. They dispense with peer review and either hoodwink the unwary into serving pro bono on their boards or as editors or, if nobody is coming forward, they simply steal details from the internet. The very visibility of most academics - a necessary aspect of contemporary academic life - is exploited by the predators. It is never to our advantage.

Therefore, in addition to our personal vigilance regarding predatory publishers, we must educate our colleagues, peers and students. Editors must ensure that the situation regarding predatory publishing is prominent in their journals and at Journal of Advanced Nursing (Darbyshire , McKenna, Lee \& East, 2017) and Nursing Open (Watson, 2018b) we have been doing this. Umbrella organisations such as INANE (the International Association of Nurse Editors) (https://nursingeditors.com/tag/predatory-publishers/; accessed 26 November 2018) have spoken and major journals such as Nature use their blog (https://www.natureindex.com/news-blog/the-undercover-academic-keeping-tabs-onpredatory-publishing; accessed 26 November 2018) to expose the excesses of the predatory publishing industry. Any readers with doubts about the veracity of my claims should refer to these resources which also expose how the predatory publishers can be persuaded to publish bogus articles, add animals to their editorial boards and publish a string of obscenities (Mazières \& Kohler, 2005).

However, little will happen until universities act internationally, and I 'have a dream' that they will. The most obvious action they could take would be to participate in creating 
inclusive 'white' lists of journals considered acceptable destinations for their scholarly outputs. They need not be concerned with keeping up to date with the predatory publishers and creating 'black' lists of journals and should exhort or oblige their academic staff to publish exclusively in those journals on their approved lists (Watson 2017b). The details of any such schemes are best left to individual universities, but having articles in predatory journals discounted in promotions or even leading to negative consequences is surely possible. Creating lists is eminently possible. At a glance PubMed, Medline, Web of Science, Scopus, Directory of Open Access Journals, the Clarivate list of SCI journals and their Emerging Source Citation Index and other lists could be consulted. These are lists - often overlapping - of credible journals. If academics consider that there are journals not on these lists which should be, then individual cases could be made.

Sadly, instead of focusing on trying to eliminate predatory journals, research funding bodies seem more obsessed with reducing the excessive ('excessive' being ill-defined) profits of the academic publishing industry. Take the European Community Plan S (https://ec.europa.eu/commission/commissioners/2014-2019/moedas/announcements/plan-s$\underline{\text { and-coalition-s-accelerating-transition-full-and-immediate-open-access-scientific en; }}$ accessed 26 November 2018) which will prevent publication in so-called 'hybrid' journals the vast majority of academic journals - in favour of a handful of purely open access journals. This way, a very exclusive list will be generated, and I fear that without an element of quality control, this will create a field day for the online open access predatory publishers. If we are not careful, we will get the science we deserve.

\section{Roger Watson}

University of Hull, UK 


\section{References}

Darbyshire, P. , McKenna, L. , Lee, S. F. and East, C. E. (2017), Taking a stand against predatory publishers. J Adv Nurs, 73: 1535-1537. doi:10.1111/jan.13004

Mazières, D., \& Kohler, E. (2005) Get me off your f*****g mailing list. International Journal of Advanced Computer Technology. Available from: http://www.scs.stanford.edu/ dm/home/papers/remove.pdf [last accessed 10 February 2017].

Watson R (2017a) Beall's list of predatory open access journals: RIP. Nursing Open 4: 60.

Watson, R. (2017b). Publishing in predatory journals is criminal Times Higher Education 10 August https://www.timeshighereducation.com/opinion/publishing-fraudulentjournals-criminal

Watson R (2018a) Predatory publishing continues Nursing Open DOI: 10.1002/nop2.226

Watson, R. (2018b), Fighting the fakes. Nursing Open, 5: 454-454. doi:10.1002/nop2.210 